\title{
O PSICÓLOGO BRASILEIRO NO SUAS: QUANTOS SOMOS E ONDE ESTAMOS? ${ }^{1}$
}

\author{
Joao Paulo Macedo \\ Adrielly Pereira de Sousa \\ Davi Magalhães de Carvalho"l \\ Mayara Alvez Magalhães ${ }^{\mathbb{I I}}$ \\ Francisca Maira Silva de Sousa \\ Magda Dimenstein ${ }^{\Phi}$
}

\begin{abstract}
RESUMO. O Sistema Único da Assistência Social (SUAS) provocou a expansão e a interiorização da profissão de psicólogo em todo o país. Objetiva-se com este estudo mapear a presença desse profissional no SUAS, identificando quantos somos e onde estamos atuando nesta política. Realizou-se um estudo descritivo-exploratório, de natureza quantitativa, tendo como fonte para a coleta, organização e sistematização dos dados o Cadastro Nacional do SUAS (CadSUAS). Entre os resultados, identificou-se que o Brasil conta com 7.607 CRAS e 2.155 CREAS, distribuídos nos 5.565 municípios. Ao todo, são 8.079 os psicólogos que atuam no SUAS (6.022 em CRAS e 2.057 em CREAS). O Nordeste destaca-se como o que conta com o maior número de psicólogos em CRAS (2.252), e o Sudeste, em CREAS (706). Ademais, 92,9\% dos psicólogos do SUAS atuam em municípios interioranos. Neste contexto, entende-se o SUAS como um importante dispositivo de capilarização da atuação do psicólogo brasileiro para as cidades de médio e pequeno porte do país.

Palavras-chave: Centro de referência da assistência social/CRAS; Centro de Referência Especializado da Assistência Social/CREAS; interiorização da atuação dos psicólogos.
\end{abstract}

\section{BRAZILIAN PSYCHOLOGIST AT SUAS: HOW MANY AND WHERE ARE WE?}

\begin{abstract}
The Unique System of Social Assistance (USSA) caused expansion and interiorization of the profession in the whole country. This study aims to map the presence of the psychologist in Social Assistance, identifying how many and where are we acting in this policy. An exploratory-descriptive study was realized, of quantitative nature, having as source of collection, organization and systematization of the data, the National Cadastre (CadSUAS). Among the results, it is identified that Brazil counts with 7,607 CRAS and 2,155 CREAS distributed in 5,565 cities. There are 8,079 psychologists in USSA (6,022 in CRAS and 2,057 in CREAS). The northeast stands out with the major number of psychologists in CRAS $(2,252)$ and the southeast in CREAS (706). Moreover, $92.9 \%$ of SUAS psychologists acts in inner cities. Through this, SUAS is understood as an important device of capillarisation of Brazilian psychologist action for small and medium size cities of the country.
\end{abstract}

Key words: Reference center of the social assistance/CRAS; Specialist Referral Center of Social Assistance/CREAS; interiorization of the actions of psychologists.

\section{LA PSICOLOGÍA BRASILEÑA EN SUAS: CÓMO Y DÓNDE ESTAMOS?}

RESUMEN. El Sistema Único de Asistencia Social (SUAS) ha fomentado la expansión y la internalización de la profesión en todo el país. El objetivo de este estudio fue cartografiar la presencia del psicólogo en el SUAS e identificar cómo y dónde estamos actuando en esta política. Se realizó un estudio exploratorio descriptivo, cuantitativo, a partir de los datos del Registro Nacional de SUAS (CadSUAS). Entre los resultados, encontramos que hay en el país 7.607 CRAS y 2.155 CREAS distribuidos en 5.565 municipios. Hay en Brasil 8.079 psicólogos vinculados al SUAS (6.022 CRAS y 2.057 CREAS). El Nordeste se destaca con mayor número de psicólogos en el

\footnotetext{
Apoio: Programa de Iniciação Científica Voluntária da UFPI.

Doutor em Psicologia pela Universidade Federal do Rio Grande do Norte. Professor Adjunto I da Universidade Federal do Piauí , Brasil.

II Bolsita da IC Voluntária da UFPI. Graduanda em Psicologia pela UFPI, Brasil.

æ Graduando em Psicologia pela UFPI, Brasil.

$\Phi$ Doutora em Psiquiatria e Saúde Mental pela Universidade Federal do Rio de Janeiro. Associado III da Universidade Federal do Rio Grande do Norte, Brasil
} 
CRAS (2.252) y el sudeste en CREAS (706). Además, 92,9\% de los psicólogos trabajan en municipios del interior. De esta manera, consideramos el SUAS como un dispositivo importante de la capilarización de la actuación de los psicólogos para ciudades brasileñas de tamaño pequeño y mediano

Palabras-clave: Centro de referencia de asistencia social/CRAS; Centro Especializado de Referencia de Asistencia Social/CREAS; la expansión de la actuación de los psicólogos.

A década de 2000 ficou marcada para a profissão de psicólogo como aquela em que se ampliou significativamente a inserção dessa categoria profissional nas políticas públicas em todo o país. Isto só foi possível em função das inúmeras articulações e movimentações da categoria em torno das principais questões que envolvem a realidade social brasileira. Na verdade, desde o final dos anos 70 os psicólogos têm procurado construir uma nova relação da Psicologia com a sociedade brasileira, envolvendo-se com os movimentos sociais na defesa de diversas bandeiras políticas, entre elas a saúde e a saúde mental, a defesa da criança e do adolescente, o debate sobre o sistema prisional, a questão dos direitos humanos e a defesa das minorias. A finalidade era que a profissão se colocasse como protagonista da realidade social do país, construindo linhas de diálogo e estreitando as parcerias entre a Psicologia e o Estado brasileiro (Bock, 2003).

Como resultado, observou-se o maior envolvimento dos psicólogos com as lutas sociais e ações de afirmação de direitos e, consequentemente, com a ampliação do espectro de preocupações, debates e alguns engajamentos no tocante aos mais diversos problemas e dificuldades enfrentados no cotidiano da população do nosso país. No plano mais prático-profissional, observouse a ampliação dos locais de inserção dos psicólogos no mercado de trabalho ligado ao Estado, especialmente no nas políticas de saúde, assistência social e segurança pública. Daí o fato de tanto o Sistema Único de Saúde (SUS) quanto o Sistema Único da Assistência Social (SUAS) constituírem-se em importantes dispositivos de fixação (institucionalização) da profissão nos aparelhos do Estado, além de serem responsáveis pela interiorização dos psicólogos para os mais diversos municípios e localidades do país (Macedo \& Dimenstein, 2011).

Somente no SUS alcançamos o quantitativo de mais de 40 mil psicólogos vinculados a esta política, participando dos mais diversos programas e serviços que compõem os três níveis de complexidade do sistema (atenção primária, secundária e terciária), conforme revela o Cadastro
Nacional de Estabelecimentos de Saúde/CNES ${ }^{2}$. A ampliação da presença do psicólogo no SUS (e de outros profissionais) foi fruto do próprio movimento de reconceitualização da saúde, a qual é compreendida não apenas como ausência de doença, conservação da vida ou manutenção da sobrevivência, mas como um processo complexo que envolve aspectos biológicos, subjetivos, sociais, econômicas, culturais e ambientais. Neste contexto, faz-se necessário ampliar as linhas de ação e formas de acesso e a assistência pública em todo o país, de modo a oferecer ações de cuidado em que a saúde figure como um processo singular e subjetivo de negociação permanente de sentidos em um campo social e como um processo de construção e desconstrução de normas para o enfrentamento da realidade e qualificação da vida.

Com o SUAS não foi diferente. A necessidade de superar o arcaico quadro da política de favor e de clientelismo que tanto caracterizou a assistência social no Brasil fez com que fossem constituídos novos preceitos e formas organizativas, incluindo o seu financiamento pelas três instâncias de governo, para resolver os desafios e os entraves do setor (Couto, Yazbek \& Raichelis, 2010).

Tal compreensão ganhou maior densidade com a inclusão da Assistência Social no capítulo da Seguridade Social da Constituição de 1988 e com a aprovação da Lei Orgânica da Assistência Social (LOAS) em 1993, que a caracterizou como uma política não contributiva e de direito inalienável para qualquer cidadão em situação de vulnerabilidade e desproteção social (Yazbek, 1995). O problema é que os conflitos de interesses e a aplicação do receituário neoliberal (novas formas de acumulação produtiva, desregulamentação do mercado e das relações de trabalho) configuraram a Assistência Social como uma política minimamente dotada de objetivos, recursos e densidade institucional. $O$ saldo não foi outro senão a secundarização de qualquer ação pública destinada ao enfrentamento da questão social e o quadro de aprofundamento da miséria e exclusão no país (Yamamoto \& Oliveira, 2010).

\footnotetext{
2 http://cnes.datasus.gov.br/Mod_Ind_Profissional_com_CB O.asp?VEstado $=00 \&$ VMun $=$
} 
Deste modo, o que ficaria conhecido como a década dos avanços sociais, devido às garantias asseguradas pela Constituição de 1988 e pelas leis do SUS e do ECA em 1990 e da LOAS em 1993, na verdade foi marcado pela desmobilização das políticas sociais ao longo dos anos 90 e início dos anos 2000. Assim, na contramão do seu marcolegal, a Assistência Social foi marcada em todo este período por um conjunto de ações fragmentadas, desarticuladas e sobrepostas, devido à pulverização de seus segmentos em vários setores ministeriais, e devido à sua fragilidade institucional, retomou o caráter imediatista, sem muito impacto ou efetividade quanto às questões sociais.

Foi somente em 2004, com a aprovação da Política Nacional de Assistência Social do consequente Sistema Único da Assistência Social, que o Estado brasileiro passou a responsabilizar-se de fato pela promoção de um conjunto de formas de segurança capaz de cobrir, reduzir ou prevenir riscos e vulnerabilidades sociais, ou até mesmo "necessidades emergentes ou permanentes decorrentes de problemas pessoais ou sociais da população" (Couto et al., 2010, p.43). Foram então retomados os princípios da Assistência assegurados anteriormente pela LOAS/93, no sentido de estruturar tal política com um conjunto de serviços e programas baseados na organização e hierarquização das ações em rede a partir dos níveis de complexidade do sistema e sob o critério da universalidade, considerando-se a lógica da territorialidade e a centralidade na matricialidade sociofamiliar (Brasil, 2004).

A inovação proposta pelo SUAS quanto às ações da Assistência é a oferta de seguranças que visam a responder ao caráter emergencial da situação de pobreza e de desigualdade, por meio dos programas de transferência de renda, sem deixar de proceder no acompanhamento de indivíduos e famílias cujos vínculos familiares e sociais se encontrem fragilizados e/ou rompidos. As seguranças a serem garantidas pelos serviços são:

- $\quad$ segurança de acolhida, com a realização de ações de recepção, escuta profissional qualificada e informação, entre outras, e com a proposta de atuação em territórios marcados por situações de vulnerabilidade, com acompanhamento continuado;

- segurança social de renda e materiais, com acesso provisório à provisão estatal, por meio de bolsasauxílios sob determinadas condições, ou benefícios continuados decorrentes de vulnerabilidades ocasionadas ou pelo ciclo de vida e/ou incapacidade ou por emergências e calamidades;

- segurança de convívio ou vivência familiar, como serviços socioeducativos que garantam a construção, restauração e fortalecimento de laços de pertencimento e vínculos sociais (geracional, familiar, vizinhança e societários);

- segurança de desenvolvimento da autonomia e de habilidades para a construção de projetos de vida, além de estímulo à participação no fortalecimento comunitário, com o reconhecimento de pautas comuns e lutas em torno dos direitos coletivos, portanto, de cidadanização (Brasil, 2004; Couto et al., 2010).

Tais seguranças são desenvolvidas mediante a oferta pública de espaços e serviços continuados e articulados na proteção social básica pelos Centros de Referência da Assistência Social (CRAS) e na proteção social especial pelos Centros de Referência Especializados da Assistência Social (CREAS). A partir destes serviços, o olhar da Assistência volta-se para as famílias e grupos sociais de um dado território, espaço por excelência onde se manifestam as vulnerabilidades e riscos sociais, por meio de fenômenos complexos e multifacetados que perfilam as sociedades e os modos de vida na contemporaneidade, como fome, pobreza, desemprego, violência, drogas e as mais diversas formas de discriminação, além de situações de desastre e calamidade.

Foi para dar algumas respostas à realidade acima descrita que foram implantados o SUS e o SUAS, os quais, articulados com outras políticas públicas, devem responsabilizar-se pela organização das ações de saúde, pelo acesso a essas ações e pela proteção social em todo o país. Deste modo, a Saúde e a Assistência Social, em conjunto com a Previdência, formam o tripé da seguridade social no Brasil.

Outro aspecto a ser considerado é que o SUAS e o SUS, devido ao processo de municipalização, são importantes campos de empregabilidade para diversas profissões. Enquanto que no SUS, conforme dados do CNES, são registrados mais de 2,7 milhões de empregos ${ }^{3}$, no SUAS, nos últimos quatro anos, elevou-se de 140 mil para 220 mil o número de trabalhadores vinculados à Assistência (Brasil, 2011).

Os psicólogos, por exemplo, desde o início da década de 1990, têm marcado presença no SUS, especialmente nos serviços ligados à saúde mental,

\footnotetext{
3 http://cnes.datasus.gov.br/Mod_Ind_Profissional_com_ CBO.asp?VEstado=00\&VMun=
} 
a ambulatórios, a unidades básicas de saúde e a hospitais especializados. Ademais, se na Saúde há estudos sobre a presença dos psicólogos no SUS, problematizando práticas, formação e produção do conhecimento na área, incluindo pesquisas de envergadura nacional (Spink, 2007), a Assistência Social, por ser uma área mais recente de atuação dos psicólogos, é um campo mais carente de estudos, investigações e publicações quanto à atuação e a formação profissional.

As pesquisas envolvendo a presença dos psicólogos no SUAS têm focado contextos mais localizados, como a inserção dos psicólogos nos CRASs no Ceará (Ximenes, Paula \& Barros, 2009), no Rio Grande do Norte (Macedo \& Dimenstein, 2009), em Minas Gerais (Mota \& Gota, 2009; Costa \& Cardoso, 2010; Andrade \& Romagnoli, 2010) e em Campinas-SP (Senra, 2006) e a atuação dos psicólogos nos CREASs no Rio Grande do Norte (Ribeiro, 2010). Tais pesquisas têm igualmente problematizado a relação entre as práticas psicológicas e a Política da Assistência Social (Cruz \& Guareschi, 2009; Yamamoto \& Oliveira, 2010).

Apesar das importantes contribuições para a profissão que esses estudos apresentam, ainda não temos a dimensão da expansão do SUAS (CRAS e CREAS) em todo o Brasil, especialmente em relação à presença dos psicólogos nessas políticas. Disto decorre a necessidade de realizar estudos que possam acompanhar o crescimento da profissão na Assistência Social, no sentido de conhecermos a rede socioassistencial instalada em todo o território nacional bem como a distribuição dos psicólogos nessa rede, dimensionando quantos somos e onde estamos a atuar nos CRASs e CREASs de todo o país.

Neste sentido, trazemos como objetivos deste trabalho: a) mapear a rede de serviços de referência (CRASs e CREAS) do SUAS; e b) identificar quantos somos e onde estamos a atuar na política de assistência social do Brasil.

\section{MÉTODO}

Na realização deste estudo utilizamos a pesquisa descritivo-exploratória, de natureza quantitativa, tendo como fonte para coleta, organização e sistematização dos dados o Cadastro Nacional do SUAS (CadSUAS) ${ }^{4}$, uma ferramenta de gestão que é

4 Disponível em: http://aplicacoes.mds.gov.br/cadsuas de uso obrigatório e permite a atualização e o monitoramento dos serviços, da rede socioassistencial e dos demais órgãos governamentais, conselhos, fundos e trabalhadores do SUAS. Entre os serviços informados constam os CRASs e os CREASs de todo o país. O gestor municipal deve atualizar regularmente os dados, e se não o fizer, ficará em pendência junto ao Ministério do Desenvolvimento Social em relação aos seus planos de gestão e, consequentemente, será bloqueado o repasse do financiamento.

Os dados recuperados do CadSUAS foram de caráter: 1) cadastral: código identificador, entidade, data de implantação, contatos; e 2) gerencial: 2.1) recursos humanos (nome, sexo, profissão, cargo, função e vínculo); 2.2) estrutura; e 2.3) informações quanto à área geográfica de atuação, recursos utilizados na implantação, dia e horário de atendimento; contudo, no acesso liberado ao público, o aplicativo não dispõe de funções que permitam consolidar as informações de maneira a visualizar como a política da Assistencial Social tem se organizado, principalmente quanto ao número de serviços, equipes profissionais e sua distribuição em cada município, estado, região - portanto, em todo o país.

Após a recuperação das informações de cada um dos 5.565 municípios no período de julho/2010 a janeiro/2011, realizou-se a etapa de organização e sistematização dos dados com base na estatística descritiva. $O$ foco da análise se deteve em duas dimensões: a) quantidade e distribuição das unidades de referência em todo o país; b) distribuição dos profissionais que compõem as equipes de trabalho, problematizando ainda o vínculo empregatício e o nível de interiorização dos psicólogos nesta política. Neste caso, além de dimensionar a presença dos psicólogos no SUAS (quantos somos e onde estamos), discutiram-se os efeitos deste cenário para a profissão na atualidade.

\section{RESULTADOS E ANÁLISES}

\section{A distribuição das unidades CRAS e CREAS no Brasil}

Dos 5.565 municípios do país, 4.743 contam com unidades públicas da Assistência Social na proteção social básica (CRAS) e especial (CREAS). Nos dados da tabela 1 se observa que em todo o país há 7.607 unidades CRAS e 2.151 unidades CREAS, números que correspondem a um índice de cobertura de $85,23 \%$ dos municípios brasileiros assistidos por unidades de referência do SUAS. 
Tabela 1 - Distribuição dos Equipamentos SUAS no Brasil

\begin{tabular}{ccc}
\hline & CRAS & CREAS \\
\hline $\mathrm{N}$ & 598 & 195 \\
$\mathrm{CO}$ & 603 & 217 \\
$\mathrm{NE}$ & 2.489 & 836 \\
$\mathrm{SE}$ & 2.507 & 591 \\
$\mathrm{~S}$ & 1.410 & 312 \\
\hline $\mathrm{BR}$ & 7.607 & 2.151 \\
\hline
\end{tabular}

Fonte dos dados: CadSUAS Jul.2011

Desde 2003 o Estado brasileiro investe na implantação de equipamentos do SUAS com o objetivo de garantir a todos os cidadãos o acesso aos serviços socioassistenciais. O esforço de ampliação, especialmente para os CRASs, deve-se a dois motivos: a) estarem localizados em áreas de maior vulnerabilidade social e se configurarem como "porta de entrada" para o SUAS; b) serem responsáveis pela organização e gestão territorial na proteção social básica e pela disponibilização de serviços e ações neste nível de atenção. Em 2011, o número de unidades apresentou crescimento de $30 \%$ em comparação com 2009, atingindo 7.607 CRASs, concentrados em maior escala nas regiões Sudeste e Nordeste. Deste total, o MDS cofinancia 6.965 unidades, sendo 642 de responsabilidade apenas dos municípios.

Analisando-se a distribuição do CRASs em todo o país, observa-se que 4.708 municípios contam com pelo menos uma unidade de referência da proteção social básica em seu território e que 856 municípios ainda aguardam a implantação desse serviço. Entre os municípios contemplados com unidades CRAS sobressaem aqueles de pequeno porte $(70,1 \%)$, sendo que a maior parte está concentrada nas regiões Nordeste $(37,9 \%)$ e Sudeste (25,3\%). Quanto aos municípios ainda não contemplados, $98 \%$ são de pequeno porte e estão concentrados, em sua maioria, nas regiões Sudeste $(40,2 \%)$ e Sul (35\%) do país.

Tal quadro de implantação do CRAS indica não apenas o avanço no processo estruturação da Assistencial Social enquanto política pública no Brasil, mas também a construção de ações importantes para conseguir o alcance da universalidade da cobertura. Com o SUAS, aprofunda-se o processo de municipalização da Assistência, já que $75,1 \%$ dos municípios brasileiros estão habilitados na gestão básica (responsabilidade pela proteção social básica) e $6,9 \%$ na gestão plena (aquela em que se assumem todas as ações da assistência social). Dentre os 4708 municípios que contam com unidades CRASs, 57 não estão habilitados no SUAS.
Neste caso, percebe-se que a Assistência Social tem conseguido avanços na sua estrutura organizativa. Tendo o CRAS como principal indutor de ações no território, pretende-se que este equipamento desenvolva ações de vigilância social nas localidades de maior incidência de vulnerabilidade e riscos, monitorando e assistindo indivíduos e famílias e garantindo as seguranças para a sua proteção social.

A justificativa para um maior adensamento de serviços da proteção social básica nas regiões Sudeste e Nordeste do país é o fato de essas regiões concentrarem algumas prioridades. O Nordeste, por exemplo, consta como a região que concentra baixos indicadores socioeconômicos em grande parte dos municípios, sendo que as áreas rurais e do sertão nordestino são as que apresentam índices mais alarmantes. São áreas em que se concentram problemas sociais básicos (mortalidade infantil, analfabetismo, trabalho infantil, desnutrição, fome, pobreza, desemprego), e que, de um lado, estão inseridas nas realidades rural e de baixo desempenho institucional, pois os municípios são completamente dependentes das ações do governo federal; e do outro, lidam com problemas típicos de grandes centros urbanos (aumento da criminalidade e da violência, prostituição e tráfico de drogas). Além disso, o inchaço das periferias das grandes cidades aprofunda ainda mais os problemas sociais da região. Por sua vez, o Sudeste, apesar de ser uma das regiões com os melhores índices sociais, econômicos e estruturais do país, também apresenta sérios problemas sociais, devido à sua densidade populacional e a seu nível de urbanização, fatores que criam desigualdades e iniquidades entre os municípios e territórios de uma mesma localidade.

Neste caso, a Assistência Social também deve estar permanentemente atenta às diferenças presentes nos espaços urbanos - pois também ali estão a se criar novos padrões de segregação espacial -, e não ficar voltada apenas aos "territórios homogênios de pobreza" (Couto et al., 2010, p.51). Sendo assim, amplia-se a concepção do usuário do SUAS, sendo esse usuário entendido não apenas como aquele indivíduo desprovido de qualquer possibilidade de renda e consumo, portanto, pauperizado e dependente de serviços públicos. Os usuários da Assistência passam a ser também aqueles em condição de subemprego ou precarizados em seus vínculos laborais, ou ainda indivíduos inseridos no trabalho "protegido", pois em tempos neoliberais, em que o trabalho cada vez mais tem perdido o seu histórico lugar protetivo, qualquer cidadão pode, em algum momento, encontrar-se numa situação de desproteção 
(Couto et al., 2010, p. 49). Daí o entendimento de que a Assistência Social é universal, mas atende apenas aqueles que dela necessitarem.

Por outro lado, diferentemente do CRAS, que tem função preventiva e de promoção de direitos e ações de cidadanização, no CREAS ("porta de entrada" da proteção social especial) as ações buscam enfrentar situações de risco pessoal ou social para indivíduos e famílias cujos direitos estejam ameaçados ou tenham sido violados. As situações mais frequentes são violência física ou psicológica, abuso ou exploração sexual, abandono e afastamento da família devido à aplicação de medidas penais, etc. Por serem de natureza mais complexa, as ações do CREAS devem estar devidamente integradas com os órgãos do Sistema de Garantia de Direitos (conselhos tutelares, juizados da Infância e da Juventude, Ministério Público, Defensoria Pública), além de delegacias especializadas (Brasil, 2004).

Conforme visto na Tabela 1, o CREAS também aparece em franca expansão. Em 2011 o número de serviços apresentou crescimento de $75 \%$ em relação a 2009, atingindo 2.151 unidades, sendo todos cofinanciados pela governo federal. O Nordeste é a região que possui o maior número de serviços: ao todo, são 836 unidades.

Analisando a distribuição do CREAS em todo o país, observa-se que 1.105 municípios contam com pelo menos uma unidade em seu território. Entre os municípios contemplados com este equipamento sobressaem aqueles de pequeno porte $(55,7 \%)$, dos quais a maior parte está concentrada nas regiões Nordeste $(32,8 \%)$ e Sul $(21,1 \%)$. Por outro lado, todas as capitais de estado do país, assim como municípios de grande porte em geral, contam com unidades CREAS no seu território. Há somente 24 municípios de médio porte que ainda não foram contemplados com este equipamento. Percebe-se, assim, uma boa expansão de unidades CREAS em todo o país, especialmente nas cidades de maior adensamento populacional e aglomeração urbana, pelo fato de serem as localidades com maior demanda de indivíduos e famílias vítimas de violência, abuso sexual e histórico de violação de direitos.

Como última nota, é importante ressaltar que, enquanto no Governo Lula (2003-2010) a implantação do SUAS ocorreu nas regiões e localidades mais prioritárias - como, por exemplo, o Nordeste -, o Governo Dilma Rousseff (2011-2014), somente nos seis primeiros meses de gestão implantou 1.285 CRAS e 927 CREAS, ampliando o acesso tanto para localidades que já contavam com bons índices de cobertura quanto para aquelas com níveis mais deficitários. O Sudeste, por exemplo, contou com o acréscimo de 511 CRASs e 268 CREASs, enquanto o Nordeste ganhou 182 CREASs e 462 CREAS. Tal soma contabilizou para a região Sudeste a manutenção do maior número de CRASs e CREASs para Minas Gerais (1.083 CRASs e 237s CREASs) e São Paulo (927 CRAS e 216 CREASs), sendo que o primeiro concentra $43,2 \%$ do total de CRASs e $40,1 \%$ do total de CREASs de toda a região. Além disso, no Rio de Janeiro, todos os municípios do Estado contam com unidades CRAS (100\% de cobertura). No caso das demais regiões, a implantação dos novos serviços também significou a conquista de $100 \%$ de cobertura CRAS no Norte, com o Pará, Acre e Roraima; no Centro-Oeste, com o Mato Grosso e Mato Grosso do Sul; e no Nordeste, com os estados de Alagoas, Sergipe, Pernambuco, Ceará, Piauí e Maranhão. Com a implantação dos novos serviços, o Nordeste consolidou-se como a região com o maior percentual de cobertura SUAS, registrando somente $4,1 \%$ dos seus municípios sem nenhuma unidade de referência da assistencial social.

Mesmo com os avanços impulsionados pelo Governo Dilma Rousseff, é preciso corrigir algumas injustiças quanto à implantação da Assistência Social e de outras políticas públicas, especialmente na região Norte e em algumas localidades do Centro-Oeste brasileiro. Apesar de contarem com índices de fragilidade social e pobreza menores que aqueles do Nordeste, as grandes extensões territoriais e a consequente dispersão populacional que caracterizam as regiões Norte e Centro-Oeste, somadas ao fato de seus municípios contarem com estruturas simples e dependentes de maior presença técnica e financeira do Governo Federal, são fatores que dificultam a realização de ações de proteção social da população dessas regiões (Couto et al., 2010).

Enquanto nesses primeiros seis meses de 2011 foram implantados 102 CRASs e 68 CREASs na Região Centro-Oeste e 125 CRASs e 71 CREASs na Região Norte, somente na Região Sul, por exemplo, que goza de melhores indicadores sociais e econômicos, foram implantados 365 CRASs e 58 CREASs. Nesse aspecto, é indiscutível que a consolidação do SUAS depende, sobretudo, da vontade política dos gestores, trabalhadores e usuários, da mudança da cultura paternalista para com os cidadãos, do fortalecimento do financiamento, da gestão e do trabalho em rede, da efetivação da política de recursos humanos e educação para o trabalho e do trabalho de participação e controle social. Pela impossibilidade de aprofundar cada um destes fatores, deter-nos-emos no debate sobre a questão dos 
trabalhadores da assistência social, em especial sobre a presença do psicólogo no SUAS.

\section{Conhecendo os trabalhadores do SUAS no Brasil}

A questão dos recursos humanos talvez seja um dos maiores desafios para a efetivação do SUAS. Para Couto et al. (2010), a tradição não política da Assistência, estruturas institucionais improvisadas e de baixo investimento na formação de equipes profissionais e a própria fragilidade organizativa e de gestão dos municípios, por serem a maioria de pequeno porte - tudo gera graves problemas para a Política de Assistência quanto à existência de trabalhadores que atuem em caráter permanente, de maneira qualificada e em defesa dos princípios do SUAS. Ademais, o trabalho na Assistência tem outras particularidades. A principal delas é o fato de ser um trabalho imaterial, cujas ferramentas de intervenção são, por excelência, o próprio trabalhador e seu conhecimento, incluindo sua formação prático-profissional e ético-política (Merhy, 2002). Neste caso, faz-se necessário que a política de assistência avance na regulação e gestão do trabalho no setor, de modo que: a) o número de trabalhadores seja ampliado e fique compatível com as realidades locais; b) a estabilidade funcional possa ser uma realidade e uma condição para avançarmos no desenvolvimento dessa política; c) haja investimentos na formação e qualificação profissional; d) o ingresso na carreira se dê por concurso público; e) seja criada uma carreira para o setor, definindo o perfil das equipes de trabalho e uma política salarial compatível com a função realizada (Couto et al., 2010).

Em geral, o trabalho no SUAS é realizado por profissionais de nível superior, médio e fundamental, porém as equipes técnicas (CRAS e CREAS) são basicamente compostas por assistentes sociais, psicólogos, pedagogos, advogados e profissionais de outras categorias, como sociólogos administradores, terapeutas ocupacionais, fisioterapeutas e nutricionistas. De acordo com a NOB-Rh/SUAS (Brasil, 2006), na constituição das equipes se observa o porte do município, do seguinte modo: no caso dos CRAS, assegura-se a presença do assistente social e, preferencialmente, a do psicólogo ou de outro profissional de nível superior; no caso do CREAS, de acordo com a modalidade da gestão, assegura a presença do assistente social, psicólogo e advogado, sendo facultativa a presença de outros profissionais (nível superior) para as ações a serem realizadas. O coordenador (nível superior) e auxiliares administrativos e técnicos (nível médio) também compõem as equipes.

Tabela 2 - Distribuição dos Profissionais no SUAS no Brasil

\begin{tabular}{lcccccc}
\hline & N & NE & CO & S & SE & TOTAL \\
\hline Assistentes Sociais & 844 & 3.896 & 927 & 2.386 & 4.626 & 12.679 \\
Psicólogos & 551 & 2.708 & 708 & 1.398 & 2.714 & 8.079 \\
Advogados & 21 & 213 & 43 & 106 & 277 & 660 \\
Pedagogos & 365 & 1.018 & 397 & 602 & 714 & 3.096 \\
Outros & 285 & 1.035 & 400 & 714 & 707 & 3.141 \\
\hline
\end{tabular}

Fonte de dados: CadSUAS Jan.2011

Considerando os dados levantados até janeiro de 2011, no geral, contabilizamos 12.679 assistentes sociais e 8.079 psicólogos atuando em CRASs e CREASs em todo o Brasil. Quanto à composição das equipes, no geral observou-se a presença de pelo menos um assistente social em cada unidade CRAS e de dois assistentes em cada CREAS. Nota-se que esta orientação algumas vezes não é cumprida, pois há um número considerável de serviços funcionando sem profissionais do serviço social, o que está em desacordo com a NOBRh/SUAS. Por outro lado, este mesmo problema é a realidade de outras categorias profissionais, pois há uma carência significativa de psicólogos e advogados na composição das equipes.

Apesar da não obrigatoriedade, registra-se a existência de 746 municípios com 810 CRASs sem psicólogos em suas equipes. Entre eles, destacamos os CRASs das regiões Sul $(n=225)$ e Nordeste $(n=206)$, notadamente os daqueles do Rio Grande do Sul (59\%) e Bahia (21\%), os quais registram o maior percentual de serviços funcionando nessas condições. $\mathrm{O}$ quadro se agrava quando o equipamento em questão é o CREAS. Neste, de fato, não se observa o cumprimento da orientação da NOB-Rh com relação à obrigatoriedade de psicólogos e advogados comporem as equipes de trabalho. Foram registrados 157 CREASs funcionando sem a presença de psicólogos, com o destaque para os serviços que funcionam nas regiões Sul ( $n=52)$, Sudeste (27) e Nordeste (26); e a existência de outras 749 unidades que não contam com a presença de advogados nas suas equipes, sobressaindo os municípios do Nordeste $(n=200)$ e Sul $(n=191)$ que se encontram nessa mesma condição.

Conforme referido anteriormente, com os assistentes sociais ocorre o mesmo, contrariamente ao estabelecido pela NOB-Rh quanto à obrigatoriedade desse profissional na composição das equipes. 
Registra-se a falta de profissionais do serviço social em pelo menos 313 CRASs e 80 CREASs. O Nordeste é a região com maior carência deste profissional tanto em CRASs $(n=108)$ quanto em CREASs $(n=28)$, sendo a Bahia e Pernambuco os estados que registram o maior número de serviços funcionado nesta condição. Além disso, do total de serviços que funcionam sem a presença do assistente social, a maioria, na verdade, não conta com nenhum profissional de nível superior na composição de suas equipes (238 CRASs e 36 CREASs). Existem também situações em que há pelo menos um profissional de psicologia na equipe, porém não consta nenhum profissional do serviço social (75 CRASs e 44 CREASs). Tais disparidades precisam ser corrigidas de modo a cumprir o que estabelece a NOB-Rh/SUAS $\mathrm{e}$, consequentemente, fortalecer a política de recursos humanos do setor.

\section{O psicólogo no SUAS: quantos somos e onde estamos?}

Sobre a pergunta "quantos somos?", alcançamos o total de 8.079 psicólogos em unidades de referência do SUAS em todo o país, sendo que, dos 6.322 CRASs pesquisados, 5.034 CRAS contam com psicólogos, e dos 1.224 CREASs pesquisados, 1.110 contam com psicólogos em suas equipes de trabalho. No total, há 6.022 psicólogos trabalhando em CRASs e 2.057 trabalhando em CREASs em todo o país. Estes profissionais estão presentes em pelo menos $67 \%$ dos municípios brasileiros. Agora, com a implantação de mais 1.285 CRASs e 927 CREASs, somente nesses seis primeiros meses do Governo Dilma Roussef (2011-2014), há uma expectativa de que o quantitativo de psicólogos no SUAS em todo o país tenha aumentado em $20 \%$ em CRASs e $70 \%$ em CREASs.

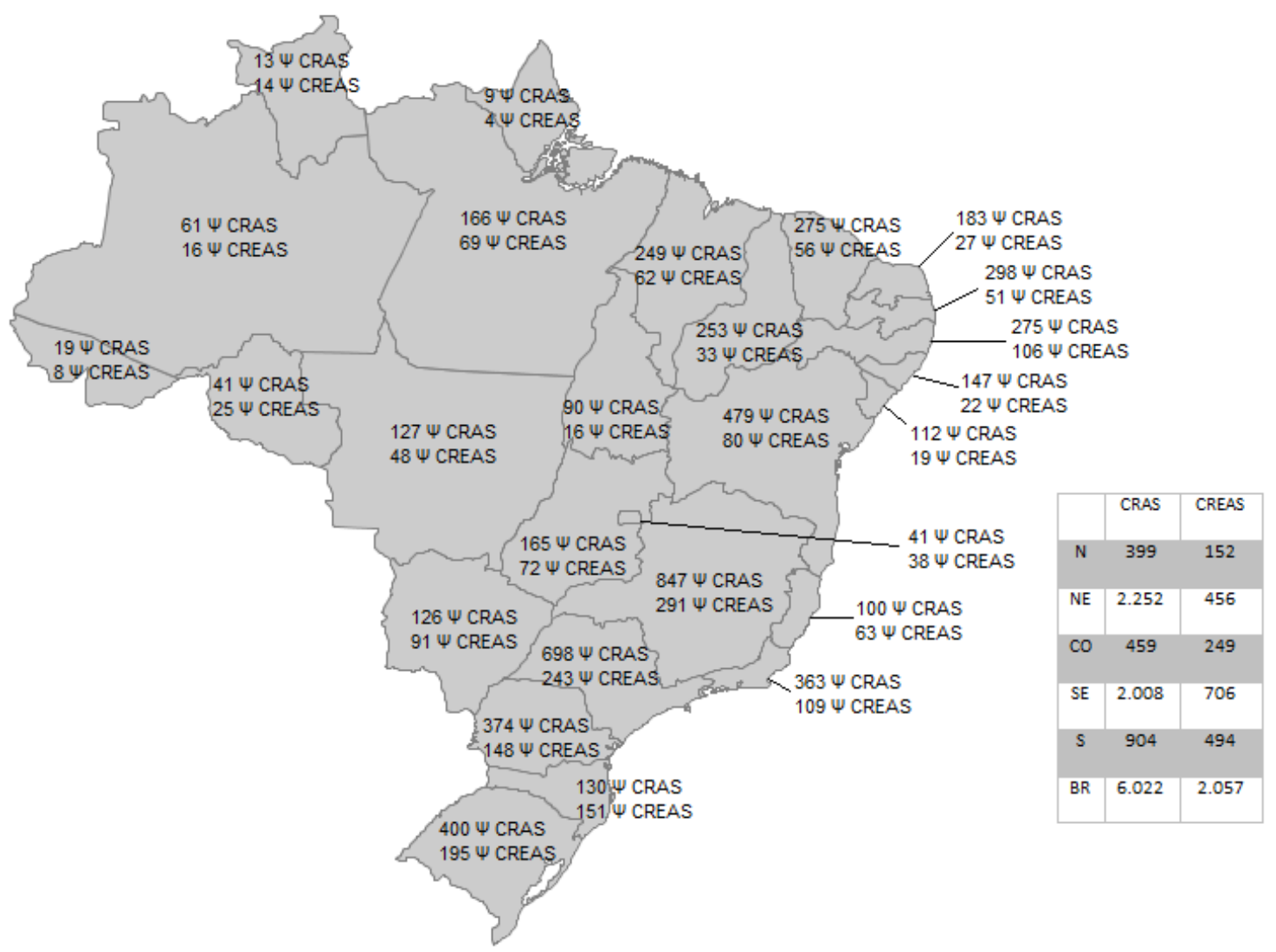

Figura 1. Mapa de distribuição dos psicólogos no SUAS

Fonte dos dados: CadSUAS Jan.2011

Sobre a pergunta "onde estamos?", o mapa com a distribuição dos psicólogos no ,SUAS estabelece que o Nordeste figura como a região em que estamos melhor representados, se comparada às demais, pois, enquanto $84,1 \%$ dos municípios do Nordeste contam com pelo menos um psicólogo atuando em CRASs e/ou CREASs, nas demais regiões o índice de municípios que contam com a presença de psicólogos é de $69,23 \%$ no Centro-Oeste, $63 \%$ no Sudeste, $62,8 \%$ no Norte e $49,5 \%$ no Sul. Quanto ao número total de 
psicólogos distribuídos por região, também sobressai o Nordeste $(n=2.708)$ como o detentor do maior número de profissionais atuando em CRASs e CREASs. A Região Norte $(n=551)$, neste caso, aparece como aquela que apresenta o menor quantitativo de psicólogos no SUAS.

Especificamente em relação aos CRASs, as regiões Nordeste e Sudeste aparecem como as que concentram o maior número de psicólogos: 2.252 e 2.008, respectivamente. No Nordeste, a Bahia se destaca pelo maior número de psicólogos em CRASs, e no Sudeste têm-se Minas Gerais e São Paulo. Esses três Estados juntos concentram 33,6\% do total de psicólogos em CRASs do país. Ainda o Nordeste sobressai quanto ao percentual de CRASs com psicólogos em seus municípios $(83,9 \%)$. O destaque neste aspecto são as localidades do Estado do Ceará (95,7\%), seguidas das de Alagoas (92,5\%), da Paraíba (92,09\%), da Bahia $(85,7 \%)$, de Pernambuco $(82,9 \%)$ e de Sergipe $(81,9 \%)$. O Piauí $(77,2 \%)$, o Rio Grande do Norte $(74,7 \%)$ e o Maranhão $(71,7 \%)$ são os estados de menor índice. Em relação ao Sudeste, 81,5\% dos CRASs da região contam com psicólogos. O Rio de Janeiro $(85,1 \%)$ é o Estado que possui o maior número de CRASs com psicólogos da região, seguido de Minas Gerais (82,4\%) e São Paulo (79,7\%), ficando o Espírito Santo com o menor percentual (74,5\%). Por fim, as localidades que concentram o maior número de psicólogos atuando em CRASs no país são as capitais: São Paulo $(n=30)$, Teresina $(n=31)$, Belo Horizonte $(n=32)$, Curitiba $(n=35)$ e Brasília $(n=41)$.

Já em relação à presença de psicólogos em CREAS, as regiões Sudeste e Sul aparecem como as que concentram o maior número desses profissionais: 706 e 494, respectivamente. No Sudeste o destaque é São Paulo e no Sul o Rio Grande do Sul. O Rio de Janeiro $(98,1 \%)$ e o Espírito Santo $(92,6 \%)$ são os Estados que concentram o maior e o menor percentual de CREASs com psicólogos na região; enquanto na região Sul os maiores índices se encontram no Rio Grande do Sul $(38,47 \%)$ e no Paraná $(29,9 \%)$. Por outro lado, os municípios que concentram o maior número de psicólogos atuando em CREASs são exatamente as três capitais sulistas: Florianópolis $(n=26)$, Curitiba $(n=27)$ e Porto Alegre $(n=35)$. É importante registrar que em oito capitais há mais psicólogos do que assistentes sociais compondo as equipes CREAS, a saber: Manaus (1:0), Porto Velho (12:10), Boa Vista (9:6), João Pessoa (4:2), Recife (4:2), Goiânia (23:15), Belo Horizonte (85:59); e o Distrito Federal (38:28).

\section{O psicólogo no SUAS: novas territorialidades,} novos desafios

No geral, quatro aspectos chamam atenção quanto à presença de psicólogos no SUAS. O primeiro é que, dos 8.079 psicólogos que atuam nessa política, 89,6\% são do sexo feminino. Trata-se, inclusive, de um dado acima da média nacional observado pela última caracterização da profissão, em que $83,3 \%$ dos psicólogos no país são do sexo feminino (Bastos, Gondim \& Rodrigues, 2010).

O segundo aspecto é que há pelo menos 632 psicólogos ocupando a função de coordenador de serviços. O Sudeste apresenta o maior número de psicólogos trabalhando nessa condição, tanto em CRASs $(n=165)$ quanto em CREASs $(n=53)$. Trata-se, portanto, de um contexto novo para a profissão, pois a coloca no âmbito da gestão dos serviços, embora, tradicionalmente, tal função seja ocupada por assistentes sociais.

O terceiro aspecto é que somente $27 \%$ dos psicólogos que atuam em CRASs são estatutários, enquanto nos CREASs este índice sobe para 37,6\%. Tal situação deixa claro que a implantação do SUAS e sua rápida expansão, apesar da significativa ampliação do mercado de trabalho para os psicólogos e outros profissionais no setor, contraditoriamente, aprofundaram a precarização das relações de trabalho nas políticas públicas. No caso dos trabalhadores dos CRAS, em que os índices são mais alarmantes, registrava-se em 2007 que 48,8\% dos profissionais ali inseridos, incluindo os psicólogos, não tinham vínculos permanentes, enquanto entre os estatutários este percentual era de apenas 25,8\%; já em 2011, o percentual de psicólogos sem vínculos permanentes subiu para $65,3 \%$, enquanto o crescimento dos estatutários foi de apenas 1,2\%. Tal situação exemplifica bem o nível da precarização do trabalho para os trabalhadores da Assistência. O Sudeste é a região que apresenta o maior número de psicólogos que ingressaram no setor por meio de concurso público: aproximadamente $50 \%$ desses profissionais se encontram nesta condição, enquanto o Nordeste mantém o maior número de psicólogos sem vínculo permanente $(85 \%)$.

O contraditório disso tudo é que esses profissionais foram contratados para desenvolver, de forma continuada e permanente, ações de proteção social para aqueles que se encontram em situação de desemprego e subemprego, ou com vínculos laborais precarizados, entretanto eles próprios, os trabalhadores da Assistência Social, vivem sob esta condição, ou seja, prestam um trabalho precarizado e eles próprios são pauperizados e desprovidos de direitos (Antunes, 
2005). Neste caso, são profissionais que convivem com a insegurança quanto ao emprego, com precárias formas de contratação, baixos salários, além da falta de perspectivas profissionais futuras, como ascensão na carreira e ausência de qualificação/capacitação profissional (Raichelis, 2010). O resultado para o SUAS não poderia ser outro: rotatividade excessiva de profissionais, descontinuidade das ações e fragilidade do trabalho das equipes - enfim, despotencialização da principal ferramenta de trabalho da política, que são seus trabalhadores.

Por último, o SUAS tem contribuído fortemente para a interiorização da profissão em todo o país, pois 92,9\% dos psicólogos que atuam em CRASs e 56,1\% dos que atuam em CREASs estão localizados em cidades do interior. Isso equivale a mais de sete mil psicólogos inseridos nos mais diversos municípios interioranos do país, muitos dos quais contam com uma população menor que 10 mil habitantes, e muitas vezes o psicólogo do SUAS que ali está consta como o único profissional da área atuando na cidade.

Por possuir o maior número de serviços, o Nordeste, e em seguida o Sudeste, são as regiões que mais têm contribuído com a interiorização da profissão no país. Nesse aspecto, não há dúvida de que a Assistência Social, ao lado da Saúde, tem tido um papel importante na reversão da proporção dos psicólogos que atuam nas capitais, caracterizando por décadas por décadas a Psicologia como uma profissão urbana e voltada para grandes centros (Rosa, Rosa \& Xavier, 1988). Atualmente, somos uma profissão com maior tendência para atuar nas cidades de médio e pequeno porte, o que aprofunda o quadro apresentado por Bastos et al. (2010), que revela o índice de $48 \%$ dos psicólogos concentrados em municípios interioranos e $32 \%$ nas capitais.

\section{CONSIDERAÇÕES FINAIS}

O novo marco regulatório da Assistência Social introduzido pela LOAS/1993 e pela PNAS/2004 produziu significativas mudanças, entre elas a exigência de novos compromissos e de um outro modo de organização, financiamento, oferta de serviços, bem como produção e gestão do trabalho, para que o SUAS fosse consolidado no Brasil como política pública (Raichelis, 2010).

Muitos autores do Serviço Social e também da Saúde - como, por exemplo, Sposati (2006) e Merhy (2002) -, têm fortalecido o argumento de que a produção e a gestão do trabalho no SUAS ou no SUS talvez constituam um dos maiores desafios para os trabalhadores atuarem na perspectiva do cuidado, da proteção social e da afirmação de direitos no âmbito das políticas sociais. O trabalho nesse âmbito estaria, assim, configurado como aquele que, no geral, encontra apoio e mediação no próprio profissional que o executa, pois sua atuação depende do conhecimento e do conjunto de manejos bem mais do que permitem sua "formação teórica, técnica e política" e as "condições institucionais de que dispõe para efetivar sua intervenção” (Raichellis, 2010, p. 761).

Nesse sentido, nós, psicólogos, precisamos pensar a Assistência Social não apenas como um novo espaço que proporciona novas territorialidades e mercado de trabalho para a profissão, mas também como um campo que aprofunda desafios tão antigos (e também novos) que acompanham nossa profissão desde quando se pretendeu inserida nas políticas públicas. O mais difícil é que não dá para pensar um projeto de compromisso ético-político para a profissão sem empenhar estratégias políticas coletivas para o enfrentamento do trabalho precarizado e de desmonte das políticas públicas. Destarte, é preciso que tenhamos uma postura crítica quanto ao Estado ao qual nos estamos associando quando, cada vez mais, fazemo-nos presentes no âmbito das políticas públicas. Além disso, devemos questionar-nos sobre a quais estratégias governamentais e relações de força estamos nos filiando quando realizamos nossa tarefa nesse âmbito (Bock, 2003; Silva, 2003).

Outro aspecto diz respeito ao desenvolvimento das habilidades e competências que caracterizam nosso fazer nas políticas públicas. Nesse aspecto, Yamamoto e Oliveira (2010) são categóricos ao referirem que o trabalho no SUAS exige dos psicólogos a "criação de novos conhecimentos e posturas" profissionais para lidar com o "contexto de pessoas vivendo em situação de pobreza", carências e desproteção social (p.21). Talvez assim, parafraseando Raichelis (2010), possamos escrever novas linhas sobre a atuação dos psicólogos nas políticas sociais para além do fatídico fazer psicológico que tanto individualiza, moraliza ou patologiza/terapeutiza a questão social. Estas são ações muito comuns entre os trabalhadores do SUAS, os quais, habituados a seu cotidiano profissional, operam com mestria dispositivos de subjetivação que ora culpabilizam os indivíduos ora tentam recuperar a capacidade (potencialidade) desses mesmos indivíduos e suas famílias, como se com seu esforço individual pudessem libertar-se dos seus problemas e da condição de pobreza que tanto os assola. 


\section{REFERÊNCIAS}

Andrade, L. F., \& Romagnoli, R. (2010). O Psicólogo no CRAS: uma cartografia dos territórios subjetivos. Psicologia ciência $e$ profissão, 30(3), 604-619.

Antunes, R. (2005). O caracol e sua concha: ensaios sobre a nova morfologia do trabalho. São Paulo: Boitempo.

Bastos, A. V. B., Gondim, S. M. G., \& Rodrigues, A. C. A. (2010). Uma categoria profissional em expansão: quantos somos e onde estamos? In A. V. B. Bastos, \& S. M. G. Gondim (Orgs.), $O$ trabalho do psicólogo no Brasil (pp. 32-44). Porto Alegre: Artmed.

Bock, A. M. B. (2003). Psicologia e sua ideologia: 40 anos de compromisso com as elites. In A. M. B. Bock. (Org.). Psicologia e o compromisso social (pp.15-28). São Paulo: Cortez.

Brasil. Ministério do Desenvolvimento Social (2006). Norma operacional básica de recursos humanos do SUAS - NOB-RH/ SUAS. Sistema Único de Assistência Social - SUAS. Brasília: O Ministério

Brasil. Ministério do Desenvolvimento Social (2011). Sala de imprensa do MDS. Brasília: O Ministério. Recuperado em 20 de outubro, 2011, http://www.mds.gov.br/saladeimprensa/noticias/2011/julho/nume ro-de-profissionais-no-suas-aumenta-57-em-quatro-anos.

Brasil. Ministério do Desenvolvimento Social. (2004). Política Nacional de Assistência Social. Sistema Único de Assistência Social-SUAS. Brasília: o Ministério.

Costa, A. F. S., \& Cardoso, C. L. (2010). Inserção do psicólogo em Centros de Referência de Assistência Social - CRAS. Gerais: Revista Interinstitucional de Psicologia, 3(2), 223-229.

Couto, B. R., Yazbek, M .C., \& Raichelis, R. (2010). A política nacional de assistência soical e o SUAS: apresentando e problematizando fundamentos e conceitos. In B. R. Couto, M. C. Yazbek, M. O. S. Silva \& R. Raichelis. O Sistema Único da Assistência Social no Brasil: uma realidade em movimento (pp. 32-65). São Paulo: Cortez.

Cruz, L. R., \& Guareschi, N. (2009). Políticas públicas e assistência social. Petrópolis, RJ: Vozes.

Macedo, J. P., \& Dimenstein, M. (2009). Psicologia e a produção do cuidado no campo do bem-estar social. Psicologia e Sociedade, 12(3), 293-300.

Macedo, J. P., \& Dimenstein, M. (2011). Expansão e interiorização da Psicologia: reorganização do saberes e poderes na atualidade. Psicologia ciência e profissão, 31(2), 296-213.
Merhy, E. E. (2002). Saúde: a cartografia do trabalho vivo. São Paulo: Hucitec.

Mota, S. T., \& Goto, T. A. (2009). Plantão psicológico no CRAS em Poços de Caldas. Fractal: Revista de Psicologia, 21(3), 521-530.

Raichelis, R. (2010). Intervenção profissional do assistente social e as condições de trabalho no SUAS. Serviço Social \& Sociedade, 104, 750-772.

Ribeiro, A. B. (2010). O psicólogo na proteção social especial: atuação junto às vítimas de violação de direitos no CREAS. Dissertação de mestrado não-publicada, Programa de Pósgraduação em Psicologia, Universidade Federal do Rio Grande do Norte.

Rosa, P., Rosa, A., \& Xavier, I. B. (1988). Quantos e quem somos. In Conselho Federal de Psicologia, Quem é o psicólogo brasileiro? (pp. 32-48). São Paulo: Edicon.

Senra, C. M. (2006). Psicólogos sociais em uma instituição pública da Assistência Social: analisando estratégias de enfrentamento. Tese de doutorado não-publicada, Centros de Ciências da Vida, Pontifícia Universidade Católica de Campinas-SP.

Silva, M. V. O. (2003). Relatório do $2^{\circ}$ seminário nacional de psicologia e políticas públicas. Políticas públicas, psicologia e protagonismo social. Brasília: Conselho Federal de Psicologia.

Spink, M. J. (Org.) (2007). A psicologia em diálogo com o SUS: prática profissional e produção acadêmica. São Paulo: Casa do Psicólogo.

Sposati, A. (2006). O primeiro ano do Sistema Único de Assistência Social. Revista Serviço Social \& Sociedade, 87, 96-122.

Ximenes, V. M., Paula, L. R. C., \& Barros, J. P. P. (2009). Psicologia comunitária e política de assistência social: diálogos sobre atuações em comunidades. Psicologia: ciência e profissão, 28(4), 686-699.

Yamamoto, O. H., \& Oliveira, I. F. (2010). Política social e psicologia: uma trajetória de 25 anos. Psicologia: teoria e pesquisa, 26(26), 9-24.

Yazbek, M. C. (1995). A política social brasileira dos anos 90: a refilantropização da questão social. Cadernos Abong. Políticas de Assistência Social. 1 (1), 15-24.

Recebido em 12/09/2011 Aceito em 15/11/2011
Endereço para correspondência:

João Paulo Macedo. Universidade Federal do Piaú, Campus Ministro Reis Velloso, Departamento de Psicologia. Av. São Sebastião, 2819, Reis Veloso, CEP 64202-020, ParnaíbaPI, Brasil. E-mail: jpmacedo@ufpi.edu.br. 